\title{
A new method for teaching physical examination to junior medical students
}

This article was published in the following Dove Press journal:

Advances in Medical Education and Practice

18 February 2016

Number of times this article has been viewed

\section{Meelad Sayma \\ Hywel Rhys Williams}

Peninsula College of Medicine and Dentistry, Plymouth, UK
Correspondence: Meelad Sayma; Hywel Rhys Williams

Peninsula College of Medicine and Dentistry, John Bull Building, Tamar Science Park, Plymouth PL6 8BU, UK Emailmeelad.sayma@students.pcmd. ac.uk; Hywel.williams@students.pcmd. ac.uk
Introduction: Teaching effective physical examination is a key component in the education of medical students. Preclinical medical students often have insufficient clinical knowledge to apply to physical examination recall, which may hinder their learning when taught through certain understanding-based models. This pilot project aimed to develop a method to teach physical examination to preclinical medical students using "core clinical cases", overcoming the need for "rote" learning.

Methods: This project was developed utilizing three cycles of planning, action, and reflection. Thematic analysis of feedback was used to improve this model, and ensure it met student expectations.

Results and discussion: A model core clinical case developed in this project is described, with gout as the basis for a "foot and ankle" examination. Key limitations and difficulties encountered on implementation of this pilot are discussed for future users, including the difficulty encountered in "content overload".

Conclusion: This approach aims to teach junior medical students physical examination through understanding, using a simulated patient environment. Robust research is now required to demonstrate efficacy and repeatability in the physical examination of other systems.

Keywords: physical examination, undergraduate, case-based approach

\section{Introduction}

There is increasing emphasis within UK medical schools in training preclinical medical students in the skills required to effectively conduct physical examination. ${ }^{1,2}$ In our UK-based mixed undergraduate and postgraduate 5-year program, regular physical examination competencies are undertaken during the first 2 years of study. ${ }^{3}$

Junior medical students often lack the clinical knowledge to be able to recall what is required to undertake a physical examination. Students often are forced to "rote" learn examination with some describing teaching of physical examination as a "show and tell exercise". 4,5 This approach is less useful when students move onto the wards and in exam situations, where knowledge has to be applied. Actual patient examination seems to offer the most effective way of learning physical examination; however, this is rarely possible for preclinical students. ${ }^{6}$

A recent paper compared students who learn with clinical signs and diagnostic considerations in mind with "rote" learners and found that the former method demonstrated better results in exam situations. ${ }^{7}$ Further research produced a lesson plan whereby differential diagnosis was used to teach physical examination maneuvers in a hypothesis-based approach to final-year medical students. ${ }^{5}$ This method of teaching 
was however designed for students with a large amount of clinical knowledge which raised the question of whether it could be applied to those students in preclinical years. ${ }^{5}$

Focus groups consisting of senior medical students highlighted that medical students found particular difficulty in recalling musculoskeletal (MSK) and motor examinations in their second-year examinations. This finding, along with recent calls to update teaching of MSK examination skills for UK medical students and national concerns of curriculum neglect, highlighted a need for the development of more effective teaching methods specifically in MSK examination. ${ }^{8-10}$ This project discusses the development and production of a case-driven teaching method, piloted in peer-to-peer small-group MSK tutorials that targeted preclinical medical students (years 1 and 2).

\section{Practice points}

1) The ability to perform effective physical examination is a key requirement of medical training; 2) Physical examination skills are most effectively learnt by practicing on patients, which preclinical medical students are rarely able to do; 3) A pilot "core clinical case"-based approach offers simulated patient experiences to preclinical students; 4) These hand-picked core clinical cases were constructed to promote learning through understanding the purpose of physical examination maneuvers.

\section{What is "rote" learning?}

Rote learning is a form of passive learning, achieved through repetition. ${ }^{11}$ Although it can be deemed as a necessary form of learning in order to excel at medical school, it is less useful when this information needs to be applied to appreciate the significance of abnormal findings. , $^{511,12}$

\section{Methods}

Cycles of "planning, action, and reflection" were used to develop this model, incorporating feedback with experiential learning into lesson plan development. ${ }^{13,14}$ Feedback was given by students after each session using Likert scales which assessed attitudes toward the lesson layout; there was also room allocated in each questionnaire for "added comments" which were thematically grouped for reflection. ${ }^{15,16}$ Senior medical students also attended sessions to give peer-to-peer feedback.

\section{Planning}

The goal of this project was to develop a model whereby preclinical medical students are able to learn through understanding the basis of physical examination maneuvers, while not possessing the depth of clinical knowledge that students would have in the later years of their studies. The constructivist learning theory was utilized as a basis for this project. ${ }^{17}$ The initial application of this theory is: 1) Developing meaning: present a clinical case and examination; 2) Developing understanding: explain and discuss relevant basic science; 3 ) Assigning significance to experience: further discussion on case and situational judgment test style questioning to put learning in context.

Three core clinical cases (CCCs) were selected to "trigger" student identification of pertinent points during physical examination of each joint. This provides a focus to student learning on understanding the purpose of the physical examination, with the aim of discouraging "rote" learning. The teaching session was structured to follow the natural pathway of a patient presentation in a clinical setting (eg, hospital or primary care). The session was followed by a discussion of basic science, pathophysiology, management, and multiplechoice questioning.

The structure of the session is: 1) Presentation; 2) History; 3) Physical examination (Case 1 - tutor-led, Cases 2 and 3 - student-led); 4) Investigations; 5) Diagnosis; 6) Basic science and pathophysiology; 7) Management; 8) Review questioning.

This model structure was repeated for each case, dividing the teaching session into a 24-point process, repeating the physical examination three times with a different case scenario. In-depth PowerPoint slides were developed to support the process, recognizing that this has been ranked as the most effective mode of teaching for medical students. ${ }^{18}$ Each session was delivered in a 2-hour format as a supplement to the medical school curriculum and before any formal MSK examination teaching had taken place in order to ensure that students had no prior knowledge of MSK examination principles. Each CCC was specifically chosen with the physical examination in mind. A short case description was constructed based on a "famous" case in order to aid recall and stimulate discussion (eg, Henry VIII and a presentation of acute gout). ${ }^{19}$ This was followed by an opportunity for students to pick out pertinent points from the history, for example, history of high alcohol use, to aid and develop case understanding, and again aid CCC recall. A physical examination was then conducted, demonstrating pertinent maneuvers and findings associated with the CCC. This was followed by summary of investigations, diagnosis, management, and basic science to help develop case-based thinking. At the 
end of each CCC, a review of the material covered was conducted using multiple-choice questions.

\section{Action}

The session was led and delivered by clinical-year medical students recognizing that the use of clinical-year medical students to deliver physical examination teaching to preclinical medical students has been shown to be effective, particularly in teaching MSK examination, with some evidence showing similar efficacy to faculty tutors. ${ }^{20-22}$ Combining this approach with "hands-on" experience for students has also been shown to be an effective learning method for medical school students. ${ }^{23}$

Sessions of up to 20 preclinical-year medical students with no previous MSK physical examination teaching were undertaken. An additional clinical-year medical student was present to observe each session with the aim of identifying improvements that could be made from the early pilot sessions. The 2-hour sessions were held fortnightly in a medical school life science resource center utilizing anatomy models and actors.

\section{Observation and reflection}

The initial pilot session was filmed to aid feedback and reflection. Feedback forms contained a mixture of Likert questions and unstructured text-free spaces. The feedback was thematically organized and summarized following each session to facilitate improvements in subsequent sessions. Throughout the development of the teaching model, key changes were made to tailor sessions to the emerging understanding of the capability of preclinical medical students. The final trial session was led by three senior medical students each delivering a different $\mathrm{CCC}$, to demonstrate inter-teacher resource capability.

\section{Results and discussion}

\section{Three key lessons}

Having repeated this lesson style with numerous cohorts of students while developing the lesson plan, this section discusses some of the key challenges identified during development and the approach taken to mitigate these challenges.

\section{Content overload. Taking focus away from the exam with the rest of the case}

Nine out of 20 of the first cohort of attendees found the teaching to be "too long and content heavy".

The feedback given considered early sessions to be "too content heavy", with some requesting longer breaks during the sessions - the peer observer noted that some students were not able to recall all key parts of the physical examination in these sessions, taking away from the end goal. This point highlights that teaching and learning are very different. ${ }^{24,25}$ Teaching allows the student to develop through being shown how to learn, not a teacher demonstrating their knowledge. ${ }^{26}$ Applying knowledge requires understanding, which "rote" learning does not achieve; however, the density of content was seen to also be a hindrance and has been demonstrated to reduce retention. ${ }^{27}$

It is important to note that when preparing for similar sessions, experience is necessary to build CCCs that complement each other when teaching physical examination, without being too content heavy. In applying these points, many of the latter sessions received more positive feedback, with all students (40/40) finding the teaching fairly or very "clear and easy to follow".

It was also essential to move away from just "covering the content" which can result in the reduction of the information learned to facts and details and to promote deeper understanding so that the students can apply their new knowledge. ${ }^{28}$ The focus of the learning for medical students was advised to be a few main points that were considered to be "essential to know". This theory was applied in later CCC sessions by placing the main emphasis on the physical examination, while repeating key points of the examination at the end of the session.

\section{The knowledge gradient}

Three out of 20 students in the first cohort of students found it "difficult to follow" integrated anatomy and clinical examination teaching, and four out of 20 students in the second cohort of students found the content "too fast".

Feedback received from students and peers after each session was used to develop and improve the initial lesson plan. Some students found it difficult to keep up with the integrated basic science explanations. It was suggested that this could be due to a large gradient in the level of basic science understanding in preclinical-year groups. A summary of pertinent anatomy and physiology before CCC teaching began was added to each session to tackle this issue. This ensured that each student had the required knowledge when approaching and discussing anatomy and physiology during the session.

Ensuring that the students were engaged was achieved by involving the students in the teaching. Students were encouraged to answer questions, discuss, and perform the examination on the simulated patient, thus aiming to achieve active learning. Active learning has been demonstrated to improve the performance of students in examinations and understanding of concepts compared to lecture-based format; 
Table I Henry's presenting complaint

A 46-year-old male presents to you, the GP, complaining of an extremely painful left foot, which came on after he stubbed it jousting yesterday. What do we want to know?

Abbreviation: GP, general practitioner.

one quarter of students noted that they found the active learning component of teaching useful in all sessions. ${ }^{29}$ This was an important consideration when designing the lesson plan and development.

\section{Mistaken identity, demonstrating what you have learnt to your colleagues}

Key observation: A student in cohort two attempted to carry out a neurological lower limb motor examination, as opposed to an MSK examination.

Learning through observing followed by performance has been demonstrated to be an effective method of teaching physical examinations. ${ }^{30}$ Interestingly, one student, when asked to demonstrate a lower limb MSK examination to peers, began performing a pure motor and neurological exam (assessing tone, power, reflexes). Understanding the difference between these two key exams was a key learning point for preclinical medical students. This challenge highlighted that junior medical students may not fully understand the context of what they are learning - although experience of making the mistake in a hands-on approach is part of the learning experience, we began each session by defining the examination of the MSK system, putting it into context, and briefly explaining the difference between neurological examination. ${ }^{23}$ This approach is recommended when approaching teaching examination in other students.

\section{Results}

This section describes an example CCC to illustrate what was constructed and illustrate key changes made to the lesson plan in the development process.

Gout was selected with the aim of emphasizing the importance of "looking" and "feeling" in MSK examination. Each

Table 2 Exploring Henry's presenting complaint

$\mathrm{S}-\mathrm{He}$ says the pain started in his left toe

$\mathrm{O}$ - It started about an hour ago

$\mathrm{C}$ - The pain is throbbing

$R$ - The pain does not go anywhere else

A - He has noted some hard nodules on his hands and ear

$\mathrm{T}-$ The pain is constant

$\mathrm{E}-$ Nothing makes it worse

$\mathrm{S}-\mathrm{He}$ describes the pain as severe

Notes: SOCRATES, Sight, Onset, Characteristics, Radiation, Associated factors, Timing, Exacerbating Factors, Severity.
Table 3 Exploring Henry's history

PMHx: Probable diabetes, hypertension, and kidney failure

PSHx: None

Allergies: NKDA

Medications: On a diuretic for his hypertension, uses St John's Wort and Achinesia regularly

Family history: He remembers his dad, Henry VII, having a similar problem

Social history: Smokes I5/day, drinks 30 units a week

Abbreviations: $\mathrm{PMHx}$, patient medical history; $\mathrm{PSHx}$, past surgical history; NKDA, no known drug allergies.

CCC was constructed using PowerPoint, with custom animation utilized to allow students to think about numerous questions in each slide. Clinical-year medical students with at least 1-year hospital experience constructed each CCC, and key resources were utilized to ensure the development of a strong, factually correct clinical case. A simulated patient scenario was developed. This is a useful tool to develop examination skills. ${ }^{31}$

It is important to emphasize that before a CCC teaching session began, a summary of relevant anatomy and physiology needs to be discussed, utilizing life science resource center anatomy models. The importance of understanding anatomy and physiology has been shown in both physical examination and daily hospital practice. ${ }^{32,33}$ Anatomy drawings were also utilized to teach the basic knowledge required, having been discussed as a "powerful" method of teaching. ${ }^{34,35}$

The first brief case summary is designed to stimulate discussion and encourage students to ask more questions with regard to the case (Table 1). The SOCRATES mnemonic (Sight, Onset, Characteristics, Radiation, Associated factors, Timing, Exacerbating Factors, Severity) for history taking was encouraged due to its regular use and importance in

Table 4 Examining Henry's foot and ankle

\section{Look}

I. Expose lower limbs

2. Note walking aids, do bedside inspection

3. Examine footwear adaptations

4. Inspect front, sides, back, and gait

5. Ask patient to stand on toes, look for muscle wasting

6. Look for swellings, deformities, and muscle wasting

Feel

I. Ask about pain

2. Assess skin temperature over both feet

3. Look for areas of tenderness

4. Squeeze MTPJs

5. Palpate any swelling, edema, or lumps

Move

I. Active and then passive movements

2. Ankle dorsiflexion, plantar flexion, inversion, and eversion

3. Toe flexion, extension, abduction, and adduction

Abbreviation: MTPJs, metatarsophalangeal joints. 
Table 5 Review question

Which of the following are risk factors for gout? (pick three)

a. Obesity [correct]

b. Bendroflumethiazide [correct]

c. Furosemide

d. Mannitol

e. Malnourishment

f. High-protein diet [correct]

g. High-carbohydrate diet

h. High-dairy diet clinical settings (Table 2). ${ }^{36}$ An image of Henry the VIII was utilized to aid teaching with the "use of famous cases" which has previously been described to be beneficial in undergraduate teaching. ${ }^{37}$

The rest of the medical history was then discussed, with each individual part appearing as a unique "custom animation" encouraging students to recall and ask the correct question (Table 3). Probable diagnoses were then discussed, with many students in this case suggesting gout.

First session

1) Putting the lesson into context, why do we learn physical examination? (10 minutes)

2) Learning point discussion (2 minutes)

3) Clinical case 1 (45 minutes). This includes a case description, going through the structure of a history, examination of hip and then carrying out the examination of the hip followed by basic science explanation, investigations then management. $M C Q$ questioning to finish

4) Clinical case 2 (30 minutes). Case description and history taking, followed by volunteer going through examination followed by basic sciences investigations and management. MCQ questioning to finish

5) Clinical case 3 Trochanteric Bursitis (30 minutes). Case description and history taking, followed by volunteer going through examination followed by basic science, investigations management. MCQ questioning to finish

6) Summary: (2 minutes) What have we covered? Further resource advise eg, Arthritis UK website

7) Question time

Total teaching time: 2 hours.

Final session
1) (10 minutes) why do we learn physical examination?
2) (2 minutes) learning point discussion
3) (15 minutes) review anatomy of foot and ankle
4) 2 -MINUTE BREAK
5) Clinical case 1 : look and feel ( 25 minutes). This includes a case description,
going through the structure of a history, examination of hip and then carrying out
the examination of the hip followed by case-based basic science, investigations
and management explanations.
6) 5-MINUTE BREAK
7) Clinical case 2 : move (25 minutes). Case description and history taking, followed
by volunteer going through examination followed by case-based basic science,
investigations and management explanations.
8) 5-MINUTE BREAK
9) Clinical case 3 : feel, special tests (25 minutes). Case description and history
taking, followed by volunteer going through examination followed by case-based
basic science, investigations and management explanations.
10) 5-MINUTE BREAK
11) (15 minutes) MCQ questioning
12) Question time
Total teaching time: 2 hours

Figure I Development of the teaching session.

Notes: The red text denotes structural and content changes made to teaching session throughout development. From the first session to the last. Abbreviation: MCQ, multiple-choice question. 
Because this was the first CCC of the three CCC sessions, the tutor demonstrated an examination on a simulated patient - discussing expected findings and emphasizing the importance of certain maneuvers when considering a diagnosis of gout. The sections highlighted are the parts of the physical examination which were emphasized in the "gout CCC"; the other sections were emphasized in later CCCs. The physical examination was simply divided into "Look, Feel, Move", a commonly used teaching breakdown for MSK physical examination (Table 4). ${ }^{38}$

Finally, multiple-choice questions were utilized to stimulate self-learning and assess students understanding of the whole CCC (Table 5). ${ }^{39}$

Figure 1 demonstrates a typical CCC conducted through the teaching model developed where the final figure illustrates the transition from the first to completed lesson plan.

\section{Benefits}

The model developed offers preclinical medical students the opportunity to learn physical examination without the need for "rote" learning. The selection of "hand-picked" CCCs reduces the need for preclinical medical students to learn large volumes of clinical knowledge (often difficult so early on), while still being able to understand the reasoning for key physical examination maneuvers. It also gives preclinical medical students early exposure and understanding of clinical process of seeing patients from history to management which is an important factor in the educational development of medical students. ${ }^{40-42}$ Medical students also developed their medical knowledge which is another important factor in medical school performance. ${ }^{43}$

\section{Limitations}

This method has only been piloted in MSK teaching. It is important to test this method in teaching different physical examinations (eg, cardiovascular examination). This method of teaching and CCC production needs to be trialed by other tutors, medical students, and professional medical educators to demonstrate course repeatability. Since the cases need to be "hand-picked" to ensure that all maneuvers in the physical examination are covered, a significant amount of experience is required to teach using this method in a timely manner, ensuring that CCCs have critical information but without content and information overload for preclinical medical students. It is also suggested that in future sessions, objective questioning should take place to further understand how this method can be applied to other types of physical examinations.

\section{Conclusion}

Preclinical medical students rarely have the opportunity to practice physical examination on patients, which has been shown to be the most effective learning method. This article proposes the use of a CCC-based approach to teaching physical examination to preclinical medical students using a simulated clinical environment to develop an understanding of the basis of physical examination maneuvers. The CCC model offers a solution to help medical students understand and learn the basis of physical examination, giving them an option to avoid "rote" learning and removing the need for often unattainable volumes of clinical knowledge at this stage. Further testing of this model is required to ascertain whether the results of this approach can be repeated for other physical examinations.

\section{Disclosure}

The authors declare no conflicts of interest in this work.

\section{References}

1. Newcomer KL, Laskowski ER, Grande JP, Dyrbye LN. The physiatrists' crucial role in the development and implementation of a longitudinal musculoskeletal physical examination curriculum in a medical school. American Journal of Physical Medicine and Rehabilitation/Association of Academic Physiatrists. 2013;92(1):84-89.

2. Bishop JY, Awan HM, Rowley DM, Nagel RW. Development and validation of a musculoskeletal physical examination decision-making test for medical students. Journal of Surgical Education. 2013;70(4): 451-460.

3. Bradley P. Introducing clinical skills training in the undergraduate medical curriculum. Medical Teacher. 2002;24(2):209-212.

4. Ramani S. Twelve tips for excellent physical examination teaching. Medical Teacher. 2008;30(9-10):851-856.

5. Nishigori H, Masuda K, Kikukawa M, et al. A model teaching session for the hypothesis-driven physical examination. Medical Teacher. 2011;33(5):410-417.

6. Bell K, Boshuizen HP, Scherpbier A, Dornan T. When only the real thing will do: junior medical students' learning from real patients. Medical Education. 2009;43(11):1036-1043.

7. Yudkowsky R, Otaki J, Lowenstein T, Riddle J, Nishigori H, Bordage G. A hypothesis-driven physical examination learning and assessment procedure for medical students: initial validity evidence. Medical Education. 2009;43(8):729-740.

8. Blake T. Teaching musculoskeletal examination skills to UK medical students: a comparative survey of Rheumatology and Orthopaedic education practice. BMC Medical Education. 2014;14:62.

9. Walker DJ, Kay LJ. Musculoskeletal examination for medical students: the need to agree what we teach. Rheumatology (Oxford, England). 2002;41(11):1221-1223.

10. Day CS, Yeh AC, Franko O, Ramirez M, Krupat E. Musculoskeletal medicine: an assessment of the attitudes and knowledge of medical students at Harvard Medical School. Academic Medicine: Journal of the Association of American Medical Colleges. 2007;82(5):452-457.

11. Hailikari T, Katajavuori N, Lindblom-Ylanne S. The relevance of prior knowledge in learning and instructional design. American Journal of Pharmaceutical Education. 2008;72(5):113.

12. Imafuku R, Saiki T, Kawakami C, Suzuki Y. How do students' perceptions of research and approaches to learning change in undergraduate research? International Journal of Medical Education. 2015;6:47-55. 
13. Mash B, Meulenberg-Buskens I. 'Holding it lightly': the co-operative inquiry group: a method for developing educational materials. Medical Education. 2001;35(12):1108-1114.

14. Lamiani G, Meyer EC, Rider EA, et al. Assumptions and blind spots in patient-centredness: action research between American and Italian health care professionals. Medical Education. 2008;42(7):712-720.

15. Sullivan GM, Artino AR Jr. Analyzing and interpreting data from likert-type scales. Journal of Graduate Medical Education. 2013;5(4):541-542.

16. Aslam MN. Student rating as an effective tool for teacher evaluation. Journal of the College of Physicians and Surgeons--Pakistan: JCPSP. 2013;23(1):37-41.

17. Taylor DC, Hamdy H. Adult learning theories: implications for learning and teaching in medical education: AMEE Guide No. 83. Medical Teacher. 2013;35(11):e1561-e1572.

18. Thomas A, Menon A, Boruff J, Rodriguez AM, Ahmed S. Applications of social constructivist learning theories in knowledge translation for healthcare professionals: a scoping review. Implementation Science: IS. 2014;9:54.

19. Norris EM. The constructive use of images in medical teaching: a literature review. JRSM Short Reports. 2012;3(5):33.

20. Perry ME, Burke JM, Friel L, Field M. Can training in musculoskeletal examination skills be effectively delivered by undergraduate students as part of the standard curriculum? Rheumatology (Oxford, England) 2010;49(9):1756-1761.

21. Silbert BI, Lake FR. Peer-assisted learning in teaching clinical examination to junior medical students. Medical Teacher. 2012;34(5):392-397.

22. Haist SA, Wilson JF, Brigham NL, Fosson SE, Blue AV. Comparing fourth-year medical students with faculty in the teaching of physical examination skills to first-year students. Academic Medicine: Journal of the Association of American Medical Colleges. 1998;73(2):198-200.

23. Chinnah TI, de Bere SR, Collett T. Students' views on the impact of peer physical examination and palpation as a pedagogic tool for teaching and learning living human anatomy. Medical Teacher. 2011;33(1):e27-e36.

24. Vander AJ. The Claude Bernard Distinguished Lecture. The excitement and challenge of teaching physiology: shaping ourselves and the future. The American Journal of Physiology. 1994;267(6 Pt 3):S3-S16.

25. Haramati A. Teaching physiology: filling a bucket or lighting a fire? The Physiologist. 2000;43(3):117-121.

26. West KM. The case against teaching. Journal of Medical Education 1966;41(8):766-771

27. Russell IJ, Hendricson WD, Herbert RJ. Effects of lecture information density on medical student achievement. Journal of Medical Education. 1984;59(11 Pt 1):881-889.

28. DiCarlo SE. Too much content, not enough thinking, and too little fun! Advances in Physiology Education. 2009;33(4):257-264.

29. McKeachie W. Tools and tips for teachers. CBE Life Sciences Education. 2011;10(2):146-148.
30. St-Onge C, Martineau B, Harvey A, Bergeron L, Mamede S, Rikers R From see one do one, to see a good one do a better one: learning physical examination skills through peer observation. Teaching and Learning in Medicine. 2013;25(3):195-200.

31. Bokken L, Rethans JJ, van Heurn L, Duvivier R, Scherpbier A, van der Vleuten C. Students' views on the use of real patients and simulated patients in undergraduate medical education. Academic Medicine: Journal of the Association of American Medical Colleges. 2009;84(7):958-963.

32. Arraez-Aybar LA, Sanchez-Montesinos I, Mirapeix RM, MompeoCorredera B, Sanudo-Tejero JR. Relevance of human anatomy in daily clinical practice. Annals of Anatomy=Anatomischer Anzeiger: Official Organ of the Anatomische Gesellschaft. 2010;192(6):341-348.

33. Zouzias IC, Byram IR, Shillingford JN, Levine WN. A primer for physical examination of the elbow. The Physician and Sports Medicine. 2012;40(1):51-61.

34. Mavridis IN. A powerful way of teaching anatomy. Surgical and Radiologic Anatomy: SRA. 2013;35(4):365-366.

35. Clavert P, Bouchaib J, Duparc F, Kahn JL. A plea for the use of drawing in human anatomy teaching. Surgical and Radiologic Anatomy: SRA. 2012;34(8):787-789.

36. Manna A, Sarkar SK, Khanra LK. PA1 An internal audit into the adequacy of pain assessment in a hospice setting. BMJ Supportive and Palliative Care. 2015;5 Suppl 1:A19-A20.

37. Coetzee D. In the middle circle, representing the zone of proximal development, students cannot complete tasks unaided, but can complete them with guidance. Wikipedia; 2011 [updated January 28, 2015; cited January 31, 2015]. Available from: http://en.wikipedia.org/wiki/ Zone_of_proximal_development-mediaviewer/File:Zone_of_proximal_ development.svg. Accessed January 31, 15.

38. Monrad SU, Zeller JL, Craig CL, Diponio LA. Musculoskeletal education in US medical schools: lessons from the past and suggestions for the future. Current Reviews in Musculoskeletal Medicine. 2011;4(3):91-98.

39. Brady AM. Assessment of learning with multiple-choice questions. Nurse Education in Practice. 2005;5(4):238-242.

40. Johnson AK, Scott CS. Relationship between early clinical exposure and first-year students' attitudes toward medical education. Academic Medicine: Journal of the Association of American Medical Colleges. 1998;73(4):430-432.

41. Pamies RJ, Herold AH, Roetzheim RG, Woodard LJ, Micceri T. Does early clinical exposure enhance performance during third-year clerkship? Journal of the National Medical Association. 1994;86(8):594-596.

42. Basak O, Yaphe J, Spiegel W, Wilm S, Carelli F, Metsemakers JF. Early clinical exposure in medical curricula across Europe: an overview. The European Journal of General Practice. 2009;15(1):4-10.

43. Greenburg DL, Durning SJ, Cohen DL, Cruess D, Jackson JL. Identifying medical students likely to exhibit poor professionalism and knowledge during internship. Journal of General Internal Medicine. 2007;22(12):1711-1717.
Advances in Medical Education and Practice

\section{Publish your work in this journal}

Advances in Medical Education and Practice is an international, peerreviewed, open access journal that aims to present and publish research on Medical Education covering medical, dental, nursing and allied health care professional education. The journal covers undergraduate education, postgraduate training and continuing medical education

\section{Dovepress}

including emerging trends and innovative models linking education, research, and health care services. The manuscript management system is completely online and includes a very quick and fair peer-review system. Visit http://www.dovepress.com/testimonials.php to read real quotes from published authors. 